\title{
O PERCURSO DA EPIFANIA NA POÉTICA DE ADÉLIA PRADO
}

Maria do Carmo Lara de Paula*

RESUMO:

O tópico desta dissertação é a epifania na poética de Adélia Prado. Este estudo seleciona alguns poemas em seus seis livros de poesia. E constata que a obra abrange diferentes vieses da epifania, a saber: o religioso, o profano e o cruzamento dos dois.

PALAVRAS-ChaVe: Adélia Prado, poesia, epifania, religiosa, profana.

A escolha de Adélia Prado - como objeto desta dissertação - fez-se por ser ela uma poeta do nosso tempo, com um texto aparentemente simples, mas que, ao ser apreendido, desvela-se múltiplo, polissêmico, com um certo grau de dificuldade e tamanha força reveladora. A temática - 0 Percurso da Epifania na Poética de Adélia Prado - já escolhida pela complexidade do assunto e pela constância nos seis livros, a saber: Bagagem (B) 1976, O Coração Disparado (CD) 1978, Terra de Santa Cruz (TSC) 1981, O Pelicano (P) 1987, A Faca no Peito (FP) 1988 e Oráculos de Maio (OM) 1999, mostrando-se um caminho instigante e desafiador. Antônio Hohlfeldt, em artigo intitulado "A epifania da condição feminina", reitera que a poesia de Adélia Prado é marcadamente epifânica:

Adélia Prado constitui um novo discurso absolutamente inédito em que 0 prazer da revelação não se circunscreve à personagem, mas é plenamente repartido com seus leitores ... Mais do que a revelação exclusiva da divindade, a literatura de Adélia Prado termina - já que não lhe aspira explicitamente - por revelar o humano no mundo, a humanidade, enfim. (Hohlfeldt, 2000: 114)

Verifica-se que a revelação/a iluminação se estende a toda sua poética. Ela se singulariza por abarcar duas epifanias: a religiosa e a profana, como |*Mestre em Letras: Estudos Literários (Ârea de concentração: Literatura Brasileira), 2003. 


\section{EM TESE}

Belo Horizonte, v. 8, p. I-243, dez. 2004

reafirma o autor citado acima: "Comungamos, assim, com as sucessivas epifanias de Deus, da alma, da mulher, do corpo, de Eros - de nós mesmos enfim". (Hohlfeldt, 2000: 115)

Para se entender a poesia e sobretudo o topos da epifania em Prado, além da leitura e releitura dos poemas, nos dirigimos à sua fortuna crítica que possui poucos artigos acadêmicos e é escassa nas histórias literárias, mas se evidencia no crescente número de dissertações e teses, cerca de vinte e cinco, na maioria citadas pela revista Cadernos de Literatura Brasileira. Adélia Prado. Quanto aos artigos em jornais e revistas, são bem expressivos. Citamos como publicações literárias: Suplemento Cultural de 0 Estado de São Paulo e o Minas Gerais e ainda em periódicos: Jornal do Brasil, Folha de São Paulo, Estado de Minas. A bibliografia compulsada e a leitura da obra em prosa e verso nos levam a perceber ressonâncias com outros poetas e escritores.

Em entrevista a Cadernos de Literatura, a poeta reafirma estar próxima a um grupo de escritores, seus preferidos.

Cadernos: Suas referências literárias são facilmente perceptíveis - Drummond, Jorge de Lima, Bandeira, Rosa, Clarice, San Juan de La Cruz, Santa Teresa D'Ávila, a Bíblia. Como a sra. lida com esse panteão?

Adélia Prado: São autores que 1 i e conclui - "Bom estes são de minha patota. São as pessoas que eu quero comigo." (Cadernos de Literatura, 2000: 26)

E ao estudar o topos da epifania, três dos escritores incluídos na "patota" de Prado vão se chegando/avizinhando de forma enfática. Uma aproximação vai-se fazendo com um dos maiores e mais expressivos poetas do Modernismo Brasileiro - Manuel Bandeira, principalmente por sua poesia epifânica. Bandeira trabalha sobremaneira a epifania profana, mas outro matiz será visto. E ainda duas outras escritoras fazem contraponto a Prado, em escala menor: Clarice Lispector, na epifania profana e Santa Teresa D'Ávila, escritora espanhola, na epifania do sagrado erotizado.

Primeiramente, apresentamos o estudo do termo epifania na visão de teólogos, ensaístas, escritores e dicionaristas. 0 vocábulo epifania surge na teologia. A Bíblia traz significativos exemplos da irrupção de Deus, do Espírito Santo, o que constitui a epifania religiosa. E a escrita inspirada pelo divino aí 
também se enquadra. Mas o conceito do termo emigra para o literário, para o profano e outras epifanias vão surgindo, como: o arroubo, o êxtase diante de pessoas e coisas. E ainda outro viés se impõe - o cruzamento da epifania religiosa e profana. Estes vieses da epifania já evidenciam as múltiplas possibilidades deste topos e se colocam como o caminho a ser trilhado.

0 termo epifania é trabalhado por muitos críticos e estudiosos, só que eles utilizam outros sinônimos como: quidditas (São Tomás de Aquino), alumbramento (Manuel Bandeira e Davi Arrigucci), instante (instante-já de Clarice Lispector), um instante e jamais e a consagração do instante (de Octavio Paz) e a sacralização do instante (de Davi Arrigucci) e ainda bliss (de Gisela Campos).

0 topos da epifania apresenta quatro subdivisões, levando-se em conta a análise das poesias de Prado e sua aproximação com os escritores já citados.

Na primeira vertente, a epifania - através de flashes da memória de coisas, lugares, épocas e pessoas - se processa em fragmentos do passado, que são revividos, rememorados, numa necessidade de eternizar o perdido, o finito. E só através dessa evocação poética que a voz lírica pode usufruir a presença dos entes queridos e da infância, e muitas vezes esse eternizar ocorre graças ao instante-já clariciano, ao momento epifânico.

Iniciemos com "Divinópolis" (inédito em livro), poema citado em Cadernos de Literatura Brasileira.

As hastes das gramineas pesavam de sementes sob uma luz que, asseguro-vos, nascia da luz eterna. Quis dizê-la e não pude, ingurgitada de palavras minha lingua se confundia.

Cantei um hino conhecido e foi pouco, disse obrigada, Deus e foi nada.

Em meu auxílio meu estômago doeu um pouco pelo falso motivo de que sofrendo Deus me perdoaria. 


\section{EMTESE}

Belo Horizonte, v. 8, p. I-243, dez. 2004

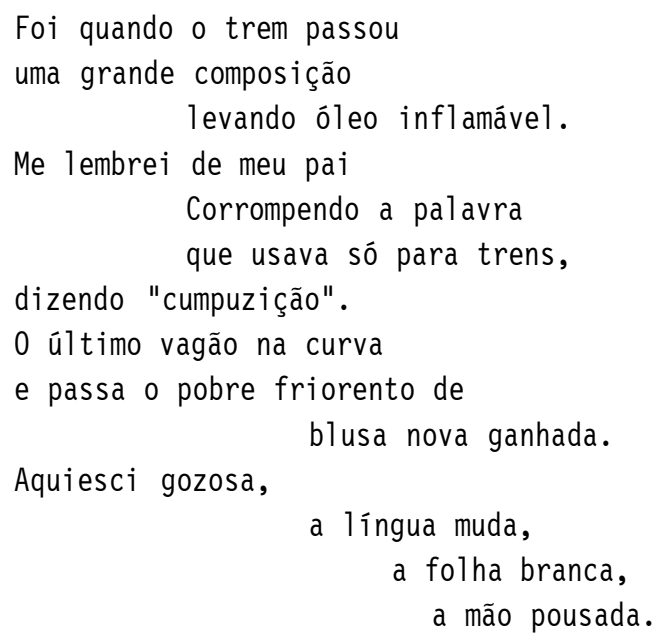

Segundo a lição de James Joyce, citada por 0lga de Sá, "é na página escrita, na alta montagem de recursos de estilo que se configura o momento epifânico. Fora da página ele não existe." (Sá, 1993: 206). Então, é através dos recursos de estilo: das metáforas, das metonímias, das assonâncias, das aliterações, de um ritmo entrecortado por pausas menores e maiores, reticências, interrogações e principalmente exclamações. E ainda através da ruptura da sintaxe e de termos que remetem à luz que a palavra se engalana e chega à iluminação.

Em "Divinópolis" os recursos de estilo são amplamente explicitados. 0 poema se constrói em versos livres, numa escrita sobressaltada, alumbrada. Os versos fluem entrecortados por vírgulas e pontos. Parecem não se conterem na oração, prolongam-se aos anteriores numa tentativa de freá-los. (Observe a visualização da poesia). A presença dos sentidos é constante. A gramínea iluminada / a luz eterna / a imagem do trem enfatizam a visão, mas a audição e 0 olfato aparecem nos versos de 18 a 25. E a inversão da frase ocorre nos versos de 1 a 5 . E ainda 0 insistente emprego da vogal a, repetida doze vezes, nos últimos quatro versos, possibilita a abertura / claridade fonética e semântica. Há pois uma interação entre forma e fundo no instante da revelação.

Quanto ao tema, o título focaliza a terra natal da escritora, a cidade mineira de Divinópolis. A primeira imagem é da gramínea banhada de luz, mas "luz eterna". A voz poética, impelida de falar, entoa um hino, agradece a Deus, mas nada a tranqüiliza. Então surge a imagem do trem e ele traz a lembrança do pai, de sua fala errada: "cumpuzição", para trens. Esse flash, essa paisagem da gramínea iluminada, do trem, remete à infância vivida em Divinópolis e à lembrança consagrada 
do pai ferroviário. É interessante ressaltar que Deus aparece três vezes, reforçando o número da Trindade Santíssima. Essa rememoração é a epifania laica, mas também a religiosa acontece no flash sacralizado do pai reforçado pelas referências a Deus, presentes no texto. As duas epifanias se cruzam, se mesclam. Esse poema exemplifica quão doloroso/ prazeroso é recordar, re-viver, a infância, as coisas, os lugares e principalmente as pessoas. Esse é o único meio de usufruir o que já é passado e está morto. É o que diz Yudith Rosenbaum: "essa ausência ou distanciamento do outro, muitas vezes instaura a necessidade de reconstruir cenas ou figuras perdidas" (Rosenbaum, 1993: 150). Não acontece aqui a rememoração da figura paterna?

Esse instante iluminado, epifanizado deixa a voz poética emudecida, extasiada, enfatizando a alta tensão desse momento (versos de 28 a 31). E a memória/ sentimento que traz/evoca o trem de ferro e a imagem do pai em "Divinópolis" é reafirmada no poema "Explicação da poesia sem ninguém pedir" e permeia a poética adeliana.

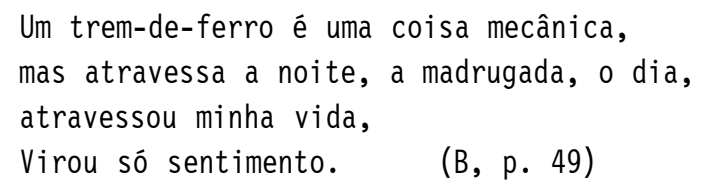

A segunda vertente é a epifania das coisas, dos lugares e das pessoas sem ênfase na abordagem memorialística. Passemos "A Diva".

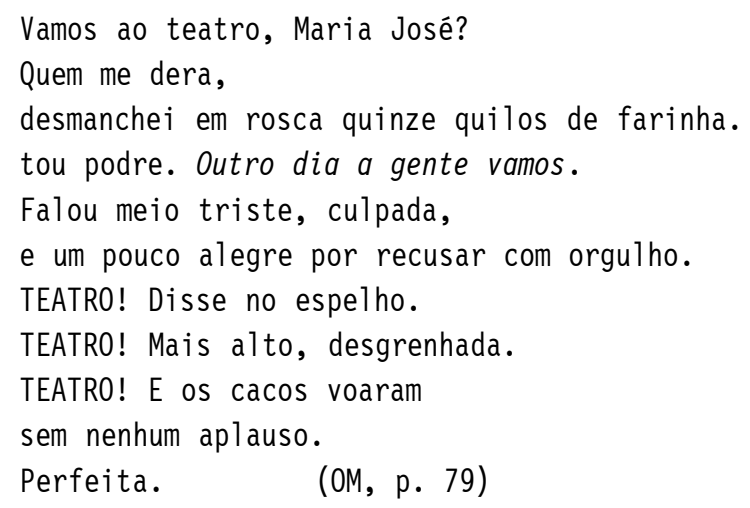

0 poema narrativo apresenta um ritmo muito pontuado. As palavras, 0 ritmo e a pontuação possibilitam o êxtase da mulher diante do espelho. Forma e fundo estão interligados nesse instante de alumbramento.

"A Diva" apresenta um paradoxo: a imagem da mulher do povo de Maria José "desgrenhada", "cacos", doméstica, de linguagem errada. E a imagem da diva (atente 


\section{EMTESE}

Belo Horizonte, v. 8, p. I-243, dez. 2004

para o título) da atriz no palco, possuída de brilho, "perfeita". A imagem do espelho reduplica essa mulher. Quando ela se olha no espelho ocorre, pois, um duplo movimento: especular/real/ desmerecedor e um outro não especular/teatral/iluminado. Esse movimento oscila também através das expressões empregadas: podre, desgrenhada, cacos x perfeita; triste $\mathrm{x}$ alegre; culpada $\mathrm{x}$ com orgulho; sem aplauso $\mathrm{x}$ perfeita.

0 espelho possibilita a essa mulher do povo, doméstica, sair da rotina para um mundo de sonhos, luzes, nesse lugar que é o espaço da representação, do teatro. E teatro reiterado de forma exclamativa faz com que a mulher se sinta uma estrela/uma diva - o que é explicado por Yudith Rosenbaum: "exclamar é estar tomado pelo objeto epifanicamente" (Rosenbaum, 1993: 177). E o universo semântico está presente através da palavra perfeita que confirma o êxtase. Esse momento de arrebatamento, esse instante de reconhecimento, é quando a epifania profana acontece de maneira acentuada, mas também remete para a epifania religiosa, pois a palavra teatro é repetida três vezes em letras maiúsculas. E esse número não é o da Trindade Santa e os nomes Maria e José não são bíblicos? Então, o cruzamento das duas epifanias acontece, mas em gradações diferentes. Em "A Diva" explicita-se a epifania profana mas toca/esbarra na religiosa.

Verifica-se, pois, que a imagem do duplo, da ambigüidade, do espelho perpassa todo o poema em diferentes níveis: duas mulheres, duas linguagens (culta e popular/errada), dois tipos de versos: curtos e extensos e duas epifanias. Essa imagem do espelho dialoga também com a história infantil da Branca de Neve e os sete anões /duas narrativas, pois o poema traz um enredo. Na narrativa da Branca de Neve, a rainha bonita, vaidosa e má pergunta ao espelho quem é a mulher mais bela. E ele responde que é a princesa - Branca de Neve. A rainha se transforma numa bruxa e vai oferecer maçãs envenenadas à princesa. 0 espelho, presente no poema e na história infantil, reflete duas mulheres: a bela, a perfeita, a diva que seria a princesa e a rainha no primeiro momento. Mas a rainha enciumada se transforma em madrasta, em bruxa. Logo a mulher doméstica, desgrenhada, do poema, reduplica a bruxa do conto.

E ainda "A Diva" enfoca a mulher e o universo doméstico, no momento da revelação, o que remete ao diálogo com Clarice Lispector.

A terceira vertente é a epifania da poesia, da escrita - tema muito recorrente na obra. Vejamos "0 poeta ficou cansado". 
Pois não quero mais ser Teu arauto.

Já que todos têm voz,

por que só eu devo tomar navios

de rota que não escolhi?

Por que não gritas, Tu mesmo,

a miraculosa trama dos teares,

já que Tua voz reboa

nos quatro cantos do mundo?

Tudo progrediu na terra

e insistes em caixeiros-viajantes

de porta em porta, a cavalo!

olha aqui, cidadão,

repara, minha senhora,

neste canivete mágico:

corta, saca e fura,

é um faqueiro completo!

ó Deus,

me deixa trabalhar na cozinha,

nem vendedor nem escrivão,

me deixa fazer Teu pão.

Filha, diz-me o Senhor,

eu só como palavras. (OM, p. 13)

0 poema se inicia quando a voz poética recusa ser arauto de Deus, alega estar cansada. E é tamanha sua ousadia, e até afronta Deus - dizendo que a voz Dele deve reboar nos quatro cantos do mundo (versos de 5 a 8). Atente para aliteração do t: Tu/Trama/teares/Tua.

A irreverência e crítica a divindade se expressa quando o eu lírico fala em caixeiros-viajantes/como arautos de porta em porta (versos de 9 a 16). A voz poética vai inquirindo, desafiando Deus ao longo do poema. 0 diálogo com Deus se evidencia pela maiúscula dos pronomes: "Teu arauto", "Tu mesmo", "Tua voz", "Teu Pão". Mas essa voz muda o tom nos últimos versos (17 a 22). Pede a Deus para trabalhar na cozinha, continuar sua vida no lar/solar. Mas a resposta do Senhor é uma revelação: "Filha, diz-me o Senhor,/eu só como palavras".

0 poeta aparece como arauto da palavra divina. Aqui, Deus se faz oráculo, pois responde e orienta o crente/a voz lírica. Oráculo segundo o Dicionário do Aurélio

1 - resposta de Deus a quem o consultava. 2 - divindade que responde a consultas e orienta o crente. 3 - Fig. Palavra, sentença ou decisão inspirada, infalivel ou que tem autoridade. 4 - Fig. Pessoa cuja palavra ou conselho tem muito peso ou inspira absoluta confiança. 


\section{EMTESE}

Belo Horizonte, v. 8, p. I-243, dez. 2004

Não é por acaso que este poema abre o livro Oráculos de Maio. E a própria Adélia explica o termo em entrevista a Elvis Gomes; em a Semana de Divinópolis 17 a $23 / 04 / 99$.

Oráculos porque a verdadeira poesia é um oráculo para mim, uma fala de uma divindade muito superior ao poeta. E como eu acredito que estou fazendo poesia de verdade, não tive vergonha, nem constrangimento de chamar meu livro de Oráculo.

A poeta reitera que a "verdadeira poesia é um oráculo", "uma fala de uma divindade" e se coloca como mediadora da divindade enquanto poeta. Ela recebe a inspiração do Espírito Santo, mas reivindica para si o direito da letra/da escrita. "Mas esta letra é minha" em "Direitos Humanos". (OM, p. 73)

Voltando à inusitada revelação no final do poema "eu só como palavras", a voz da divindade é firme, impositiva, carregada de realismo, crua, com pontuação entremeada de interrogações e exclamações e num ritmo marcado. Forma e fundo vêm juntos.

A quarta vertente é a epifania do sagrado erotizado e desejado pela voz poética - configurando a mística erótica. Considerando os conceitos estudados, pode-se concluir que eros é desejo, é atração, é procura. E que o conceito de misticismo, de Marcial Maçaneiro, abarca e resume os outros - como anseio de comunhão com Deus e experiência dessa comunhão.

Iniciemos com "Memória Amorosa".

Quando ele aparece

bonito e mudo se posta

entre moitas de murici.

Faz alto-verão no corpo, no tempo dilatado de resinas.

Como quem treina para ver Deus,

olho a curva do lábio, a testa,

0 nariz afrontoso.

Não se despede nunca.

Quando sai não vejo,

extenuada por tamanha abundância:

seus dedos com unhas, inacreditáveis! (P, p. 348)

Este poema trata da sedução do eu poético por Jonathan/Deus. "Memória Amorosa" se abre com a presença do humano. "Quando ele aparece" (letra minúscula) refere-se ao amado/homem que chega. Segundo Rita de Cássia, em tese de doutorado, 
"a voz feminina do poema é revisitada pelo amado de maneira semelhante às descrições místicas de Santa Teresa." E essa vinda deixa o eu lírico em êxtase, que será descrito a partir de "Faz alto-verão no corpo", num crescendo de imagens sensoriais até o transbordamento nos dois últimos versos. 0 verso citado explicita em toda sua pujança o erotismo através da imagem solar/alto-verão que acontece no corpo. E é percebido através do perfume das resinas e visto/apreendido através da "curva do lábio", "da testa", "do nariz afrontoso". Então, a beleza, a sensualidade do corpo é captada como algo natural, que faz parte de Eros, que leva à paixão, ao alumbramento. Aqui já aparece o Amado divino "como quem treina para ver Deus". A ambigüidade entre amado-homem e amado-Deus perpassa o texto.

A imagem do amado surge e desaparece como num mistério, a voz poética o acolhe submissa como nos poemas de Teresa D'Ávila. Só que, em Adélia, o êxtase amoroso acontece no plano físico e é aceito como parte integrante do ser e vivido em plenitude.

0 poema se fecha com 0 instante epifânico da voz lírica seduzida pela lembrança. Observe que os versos 11 e 12 enfatizam o êxtase físico que se mistura ao espiritual, reforçado pela frase exclamativa e pelo termo abundância.

A partir do que vimos neste percurso pela poesia de Adélia Prado, verificamos que o fio condutor que tece, costura a tessitura é o cruzamento do profano com o religioso, mas com a supremacia do divino, que acontece num instante iluminado, de revelação. Porém, os limites dessa mescla são muito tênues e delimitar as epifanias torna-se às vezes impossível.

Achamos relevante reafirmar que em Adélia, essa iluminação se dá através do emprego significativo dos recursos de estilo. E que só através do trabalho artesanal com o vocábulo (desprendendo as amarras fonéticas, sintáticas e semânticas do português formal) é possível apreender a palavra potencializada "peixe vivo com a mão". E assim atingir o verso iluminado, a escrita epifânica.

Verificamos que os vinte e dois poemas interpretados são epifânicos e que vinte apresentam o cruzamento nas duas instâncias. Então, concluímos que a epifania e o cruzamento são marcas que se estendem à poética de Adélia Prado, singularizando-a no quadro da literatura brasileira. 


\section{EM TESE}

Belo Horizonte, v. 8, p. I-243, dez. 2004

ABSTRACT :

The subject of this paper is epiphany in Adélia Prado's poetry. The epiphany is a constant theme developed in her six poetry books. Her poems present religious and profane epiphanies and a mixture of them.

KEY WORDS: Adélia Prado, poetry, epiphany, religious, profane.

\section{REFERÊNCIAS BIBLIOGRÁFICAS}

CADERNOS DE LITERATURA BRASILEIRA. Rio de Janeiro: Instituto Moreira Salles, n. 9, jun. 2000. (Fascículo Especial sobre Adélia Prado)

HOHLFELDT, Antônio. A epifania da condição feminina. Cadernos de Literatura Brasileira. Rio de Janeiro: Instituto Moreira Salles, n. 9, jun. 2000. (Fascículo Especial sobre Adélia Prado)

PRADO, Adélia. Poesia reunida. (Bagagem, o coração disparado, Terra de Santa Cruz, o pelicano, A faca no peito). São Paulo: Siciliano, 1999.

ROSENBAUM, Yudith. Manuel Bandeira: uma poesia de ausência. São Paulo: Editora da Universidade de São Paulo; Rio de Janeiro: Imago, 1993.

SÁ, $01 \mathrm{ga}$ de. A escritura de Clarice Lispector. Petrópolis: Vozes; Editora da PUC-São Paulo, 1993. 